\title{
Multivariate analyses of selected mechanical properties of dry bean grain
}

\author{
Hakan Kibar \\ Department of Seed Science and Technology, Faculty of Agriculture and Natural Sciences, Abant Izzet Baysal University, \\ Bolu, Turkey
}

Received September 3, 2014; accepted January 3, 2015

\begin{abstract}
A b s t r a c t. The direct shear test are widely used to measure the bulk material properties for economical design of bulk handling equipment and to estimate wall pressure inside storage structures, namely their bulk density, the angle of internal friction, shear strength, Poisson ratio, and lateral pressure ratios are required. Tests were conducted at thirty six different shear speeds (between 0.30-1.00 $\mathrm{mm} \mathrm{min}^{-1}$ ) and three different normal stresses were applied $(60,120$ and $180 \mathrm{kPa})$. The angle of internal friction, Poisson ratio, and lateral pressure ratios demonstrated fluctuations depending on the shear speeds. The results of the principal component analysis indicated that the first three principal components accounted for $97.40 \%$ of the total variability among the thirty six different shear speeds for all the traits investigated. The first principal component was the most important. In the result of principal component analysis, the shear speeds were divided into seven clusters. The pressures were decreased and increased with the change of the angle of internal friction and the lateral pressure ratio. The data obtained from the study will be useful in the structural design of dry bean bins to calculate loads on bins from the stored material and grain handling equipment.

K e y w o r d s: dry bean, direct shear test, the angle of internal friction, principal component analysis, cluster analysis
\end{abstract}

\section{INTRODUCTION}

Dry bean is one of the oldest cultivated grains in the world. Low-cost dry beans contain vitamins, minerals, soluble dietary fiber, and protein. A serving of dry beans is rich in B-vitamins, iron, calcium, potassium, phosphorous but is low in sodium and calories. Dry beans also contain high levels of complex carbohydrates with a low to moderate glycemic index. Carbohydrates with a low glycemic index such as the ones that are found in dry beans are

Corresponding author e-mail: hakan.kibar@ibu.edu.tr able to provide energy over a long period of time by being slowly released into the bloodstream to provide sustained energy levels (USDA, 2012).

Some of the mechanical properties are becoming inreasingly important for improvement of the design of storage structures and conveyance facilities of dry bean materials in modern agriculture. These mechanical properties have been studied with the direct shear test for various agricultural materials which by many researchers such as Molenda et al. (2001) for wheat, corn meal, and soybean meal, Zou and Brusewitz (2001) for marigold, and Moya et al. (2002a) for barley, corn, oat, sunflower, lentil vetch, and wheat. Agricultural enterprises have increased in size and have incorporated mechanized feeding systems which require reliable grain handling equipment. Improved farming techniques and marketing considerations have contributed to the increased demand for more economical approaches to dry bean storage. Storage of dry beans whose supply or demand fluctuates in a predictable manner, especially seasonal produce, is necessary to increase availability. It is essential that processors maintain stocks of dry beans; therefore, storage is necessary to buffer demand. The quantities of dry beans held in store and the times of storage vary widely for different cases, depending on the above considerations. The primary objective is to maintain the best possible quality during storage, and hence avoid spoilage during the storage period. Dry beans are commonly stored in vertical structures, in particular in reinforced concrete silos and in steel bins. An economical layout of the various silos and bins is essential. The foremost advantage of vertical storage is the efficient discharge of the dry bean 
by gravity flow. Steel bins have gained popularity rather recently. In addition to their advantages over concrete silos with respect to initial costs and erection time, steel bins are more easily accessible through manholes and are more easily fitted with aeration equipment and temperature-measuring instrumentation.

Knowledge of real moisture distribution of dry bean and components at harvest is an essential requirement for designing efficient processing operations and obtaining desired high quality products. The moisture content of beans has an influence on their mechanical properties and wall pressure as well as the dry bean quality.

The direct shear testing is a standard testing method employed for estimation of grain shear strength parameters. The direct shear test is widely used to measure the agricultural material properties for the design of storage structures, processing equipment, and machines (Härtl and Ooi, 2008).

The direct shear cell can be used according to ASTM standards D3080-90 and D6128-97 (ASTM 2000a, b) to obtain a yield locus with fairly reproducible results (Zou and Brusewitz, 2001).

The angle of internal friction is a measure of the force required to cause particles to move or slide on each other. Stable slopes and hang-ups in bins are highly dependent on the angle of internal friction. Internal friction is influenced by many parameters such as particle surface friction, shape and hardness, size, and size distribution. It is needed for calculating the lateral pressure on the walls of storage silos and in the design of gravity flow in bins and hoppers (Ganesan et al., 2005).

The application of numerical methods to silo design has made possible a better understanding of the behaviour of stored material inside silos. The complexity of the cases studied with this technique has increased because technological improvements have made more powerful tools available. With these methods, it is possible to consider some new material properties, such as the angle of internal friction, Poisson ratio, and the modulus of elasticity in the analysis (Moya et al., 2006).

The objective of this research was to determine the angle of internal friction, Poisson ratio, lateral pressure ratio, and silo wall pressures at different shear speeds of dry bean grain for design of storage structures as well as peeling and processing equipment. Another objective of the study, the structure of variability in different shear speeds using multivariate statistical analyses (principle component analysis, cluster analysis) was to determine. These parameters can be used in silo modelling and processing equipment using the finite element method in order to better understand the interaction that exists between the grain and the storage structure.

\section{MATERIAL AND METHODS}

The experiments were carried out with the Zülbiye variety that is widely cultivated in the Black Sea region of Turkey during the 2010-2011 harvest periods. The dry bean variety ( $c v$. Zülbiye) was provided by the Black Sea
Agricultural Research Institute in Samsun, Turkey. Firstly, the dry beans brought to the laboratory were manually cleaned to remove all foreign matter such as dust, dirt, stones, and chaff as well as immature, broken seeds. To determine the average size of the dry bean, a sample of 100 dry beans was randomly selected. In this study, 100 seeds were measured. The length (L), width (W), and thickness $(\mathrm{T})$ were measured using a digital caliper reading to $\pm 0.01 \mathrm{~mm}$ accuracy. The initial moisture content of dry bean after harvest was determined by oven drying at $80 \pm 5^{\circ} \mathrm{C}$ for $24 \mathrm{~h}$ (AOAC, 1984). In order to cool the dry beans, the dried samples were transferred into a desiccator. The samples were dried under these conditions to reach constant dry weight. The dry bean grains were left for natural drying in the laboratory to decrease the desired moisture level. After natural drying, the dry bean was kept in closed plastic bags and stored in a refrigerator at $4{ }^{\circ} \mathrm{C}$ until further use. The dry bean grains were kept in the refrigerator for about 15 days. They were prepared for tests by keeping them under controlled laboratory conditions for at least $24 \mathrm{~h}$ prior to tests. The temperature of $23 \pm 2^{\circ} \mathrm{C}$ and relative humidity of $65-75 \%$ were maintained as the main environmental parameters.

A normal load was applied to the specimens and the specimens were sheared across the pre-determined horizontal plane between the two halves of the shear box. Measurements of shear load, shear displacement, and normal displacement were recorded. The test was repeated for two or more identical specimens under different normal loads. A shear test was conducted to determine the angle of internal friction $(\varphi)$ and cohesion of a sample using a direct shear cell installed in a universal testing machine. The testing system consisted of a direct shear cell (standard in soil testing), including dead weight as normal load, and the universal testing machine (Zou and Brusewitz, 2001). The tests were conducted at thirty six different speeds (between $\left.0.30-1.00 \mathrm{~mm} \mathrm{~min}^{-1}\right)$ and three different normal stresses were applied $(60,120$, and $180 \mathrm{kPa}$, respectively). Their descriptions are presented in Table 1. Each test was replicated five times (measure 1, 2, 3, 4, and 5) depending on the type of the test.

T a b l e 1. Angles of internal friction and their description in the different shear speed (SS)

\begin{tabular}{lc}
\hline Traits & Shear speed $\left(\mathrm{mm} \mathrm{min}^{-1}\right)$ \\
\hline SS1 & 0.30 \\
SS2 & 0.32 \\
SS3 & 0.34 \\
SS4 & 0.36 \\
. & $\cdot$ \\
. & $\cdot$ \\
. & $\cdot$ \\
. & $\cdot$ \\
. & $\cdot$ \\
. & $\cdot$ \\
SS36 & $\cdot$ \\
\hline
\end{tabular}


The strength of grain depends of its resistance to shearing stresses. It is basically made up of two components: - frictional - due to friction between individual particles, - cohesive - due to adhesion between the grain particles.

The two components are combined in Coulomb shear strength equation:

$$
\tau_{f}=c+\sigma_{f} \tan \varphi,
$$

where: $\tau_{f}$ - shearing stress of grain at failure, $\mathrm{c}$ - apparent cohesion of grain, $\sigma_{f}$ - total normal stress on failure plane, $\varphi$ - angle of internal friction (angle of shearing resistance of grain).

Poisson ratio (v) was calculated with Eq. (2) developed as a function of the angle of internal friction by Qu et al. (2001):

$$
v=\frac{1-\sin \varphi}{2-\sin \varphi} .
$$

A number of equations relating the lateral pressure ratio $(k)$ to the angle of internal friction $(\varphi)$ have been proposed. The stress ratio can be also derived from the theory of elasticity as a function of Poisson ratio. Theoratical equalities relating to the issue are given in Eqs (3-5). These equalities:

$$
k=\frac{v}{1-v},
$$

Jaky (1948) (according to Lohnes, 1993) derived a relationship for the at-rest state of stress:

$$
k=\frac{(1-\sin \varphi)\left(1+\frac{2}{3} \sin \varphi\right)}{1+\sin \varphi} .
$$

Equation (5) was modified and recommended by Eurocode 1 (2006) as:

$$
k=1.1(1-\sin \varphi),
$$

where: $k$ - lateral pressure ratio, $\varphi$ - angle of internal friction, degrees.

In the study, the basic properties of the wall material were taken from the Eurocode 3 standard (2004). The steel cylindrical silo (flat bottom) created as a theoretical model in this study had height $10.0 \mathrm{~m}$, diameter $5.0 \mathrm{~m}$ and thickness $4 \mathrm{~mm}$. The wall of the silo was assumed to be made of flat steel. S235 steel was used as steel material (Eurocode 3, 2004). In this study, values concerning dry bean $\left(\gamma: 8.20 \mathrm{kN} \mathrm{m}^{-3}, \mu: 0.331\right)$ were used to calculate wall pressures. The lateral pressure ratios on the wall of the silo were calculated according to Eurocode 1. The steel wall was considered to be isotropic depending on the mechanical properties of the wall (E: $2.1 \times 10^{8} \mathrm{kPa}, v: 0.3, \gamma_{\mathrm{a}}: 80 \mathrm{kN} \mathrm{m}^{-3}$ and $\mathrm{f}_{\mathrm{yi}}: 188000 \mathrm{kPa}$ ). The storage capacity of the dry bean silo according to this geometry is $160 \mathrm{t}$.

The vertical pressure acting on a flat bottom (inclination $\alpha \leq 5^{\circ}$ ) may be taken as uniform (Eurocode 1, 2006). The vertical pressure should be determined acting on a flat bottom. The most comprehensive design standard for these loads is the new Eurocode 1, which defines different classes of the silo by the size, aspect ratio, wall roughness, and construction material and requires a range of properties to be considered for the stored solids and several different loading conditions to be examined in design calculations. In storage design, physical parameters play a role on the structure side as well as on the load side. These parameters are always subjected to some variations.

The vertical pressure acting on a flat bottom during discharge should be taken as identical to the vertical pressure at the end of filling (Eurocode 1, 2006). The vertical pressure acting on a flat bottom should be determined as:

$$
P_{v f t}(z)=\frac{P_{b}}{k} Y_{j}(z),
$$

in which:

$$
\begin{aligned}
P_{v f t}(z) & =\frac{P_{b}}{k} Y_{j}(z), \\
P_{h o} & =\gamma k z_{o}, \\
z_{o} & =\frac{A}{k \mu U},
\end{aligned}
$$

where: $A$ - plan cross-sectional area of vertical walled segment $\left(\mathrm{m}^{2}\right), P_{h o}$ - asymptotic horizontal pressure at great depth due to stored particulate solid $(\mathrm{kPa}), P_{v f t}$ - vertical pressure solid after filling $(\mathrm{kPa}), U$ - internal perimeter of the plan cross-section of the vertical walled segment $(\mathrm{m})$, $Y_{j}$ - Janssen pressure depth variation function, $z$ - depth below the equivalent surface of the solid in the full condition (m), $z_{o}$ - Janssen characteristic depth (m), $\alpha$ - mean angle of inclination of wall measured from the horizontal, degree, $\gamma$ - characteristic value of the bulk unit weight of solid $\left(\mathrm{kN} \mathrm{m}^{-3}\right), \mu$ - characteristic value of the coefficient of wall friction for a vertical wall.

The Duncan multiple range and cluster and principal component analysis (PCA) statistical analyses were used for various parameters at different shear speeds and these data were statistically analyzed using SPSS and Minitab. Cluster analyses were performed to determine which angles of internal friction were similar and dissimilar to categorize them according to different shear speed. The hierarchical (linkage) method can be chosen from the Cluster analyses. To start with, requested complete linkage clustering by selecting the furthest neighbour (the furthest neighbour is a synonym for complete linkage). In addition, PCA was applied to investigate the factor structure of these thirty six different speeds.

\section{RESULTS AND DISCUSSION}

The initial moisture content of dry bean grains after harvesting was $14.8 \%$. The moisture content of the dry bean grains after natural drying was $8.3 \%$ (dry basis). The mean values of the $\mathrm{L}, \mathrm{W}$, and $\mathrm{T}$ for dry bean were determined as $15.40 \pm 0.48,7.26 \pm 0.36$, and $5.91 \pm 0.11 \mathrm{~mm}$, respectively. 
High and low values of the angle of internal friction are indicated in Fig. 1. As seen in Fig. 1, the values of the angle of internal friction at different shear speeds ranged from 14.00 to $28.25^{\circ}$. The lowest mean value for the angle of internal friction was determined as $0.30 \mathrm{~mm} \mathrm{~min}^{-1}$ and the highest mean value was determined as $0.74 \mathrm{~mm} \mathrm{~min}^{-1}$. In addition, the values obtained for the angle of internal friction were quite different. The differences among the angles of internal friction at the different shear speeds were statistically significant at $p<0.01$. Expressed statistically, a significant difference is the difference between the values of all the angles of internal friction. Despite the statistical difference, the values of the angles of internal friction at the shear speeds are very low. Therefore, the values of the angles of internal friction of shear speeds from 0.30 to $0.38 \mathrm{~mm} \mathrm{~min}^{-1}$ are not recommended. Because these shear speeds are very low, the values of the angle of internal friction are difficult to calculate. The values of the internal friction angle can not give accurate results in the calculation of the silo wall pressures. Therefore, in terms of silos, designers can be misled. Moya et al. (2002b) reported both decreased and increased angles of internal friction at different shear speeds $(0.065$, 0.32 and $0.63 \mathrm{~mm} \mathrm{~min}^{-1}$ ) for various agricultural products (kym barley, krona barley rapeseed, eulalia chickpea, sunflower, camacho wheat, camarma triticale, senda vetch, vereda vetch, lentil vetch). The values of the internal friction angle, especially in the determination of the silo wall thickness, are used in both empirical equations and finite element software such as ANSYS and ABAQUS. In addition, it is a useful parameter for the optimum design of hoppers.

The histogram plot relating to frequency distribution of the angles of internal friction at different shear speeds is shown in Fig. 2. Each histogram displays the frequencies of certain ranges of the angles of internal friction within the sample. Summary information related to the histogram is shown in Table 2. The angle values ranged from 13.74 to $28.56^{\circ}$. 19 different classes were composed for the angle of internal friction in the histogram plot. The mean and median values for a quick check were compared. These vaare close to each other and can be said to conform to a normal distribution of data. As can be seen from Table 2, the mean value is 22.09 , while the median is 23.72 . Although

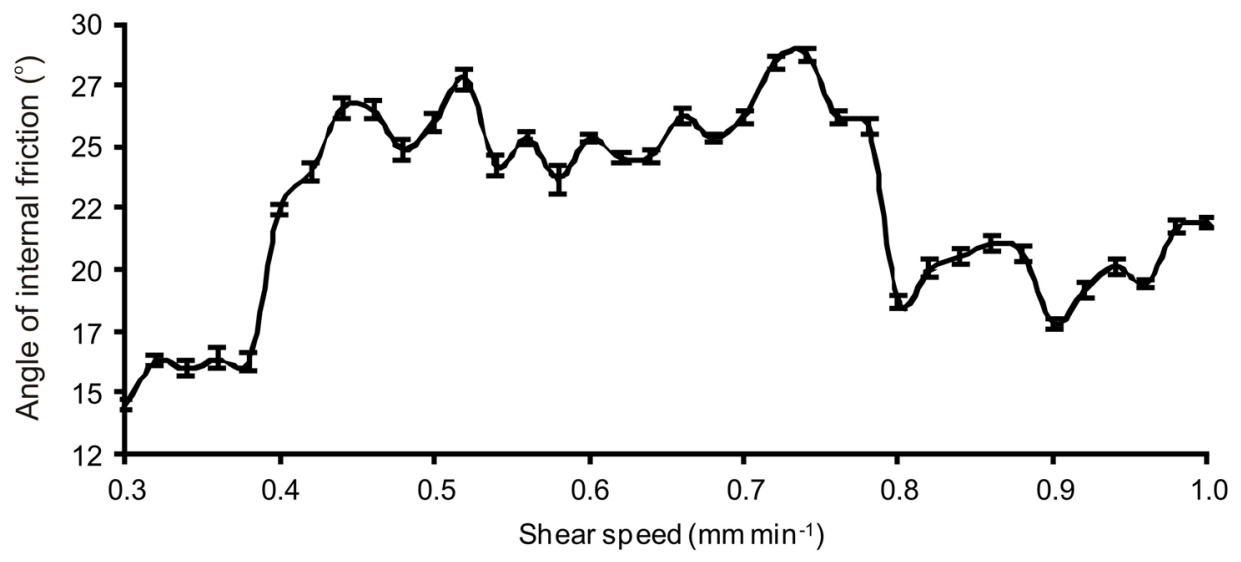

Fig. 1. Mean angles of internal friction at different shear speeds.

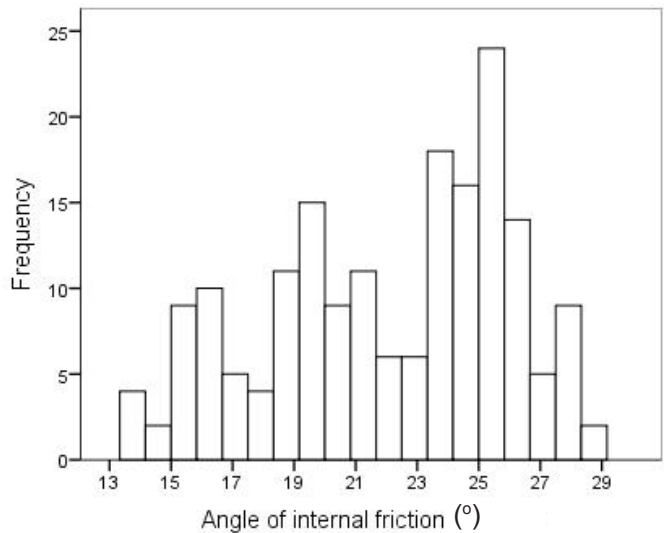

Fig. 2. Histogram plot of the angles of internal friction at different shear speeds. normally distributed, histogram data should be concerned about the Skewness coefficient. Skewness coefficient for the normal distribution must be from -1 to +1 . Skewness coefficient is $-1<-0.404<+1$ (Table 2). However, to be normal distribution, the double of the Standard error of Skewness $(0.181 \times 2<)$ must be less than the skewness coefficient. Accordingly, the angles of internal friction at different shear speeds did not show a normal distribution (0.181x2>-0.404).

Figure 3 shows the displacement curves of varying confining stresses for dry bean. The test results show that these increased at the shear stress values with the increase in normal stress $(60,120,180 \mathrm{kPa})$ for both 0.30 and $0.74 \mathrm{~mm}$ $\min ^{-1}$ shear speed. Here, the shapes concerning minimum 
T a b l e 2. Values relating to the angle of internal friction and histogram

\begin{tabular}{ccccccccccc}
\hline \multirow{2}{*}{$\begin{array}{c}\text { Measurement } \\
\text { number }\end{array}$} & Minimum & Maximum & Mean & $\begin{array}{c}\text { Standard } \\
\text { deviation }\end{array}$ & $\begin{array}{c}\text { Median } \\
\left({ }^{\circ}\right)\end{array}$ & Skewness & Kurtosis & \multicolumn{2}{c}{ Standard error } \\
\hline \multirow{2}{*}{180} & 13.74 & 28.56 & 22.09 & 3.90 & 23.72 & -0.404 & -0.940 & 0.181 & 0.360 \\
\hline
\end{tabular}


Fig. 3. Shear stress (shear speed: $\mathrm{a}-0.30, \mathrm{~b}-0.74 \mathrm{~mm} \mathrm{~min}^{-1}$ ) concerning the maximum and minimum angle of internal friction.

and maximum values in the angles of internal friction are given. Peak stresses in each two-speed were determined in $180 \mathrm{kPa}$ normal stress. However, the shear stress value at $0.74 \mathrm{~mm} \mathrm{~min}^{-1}$ and $60 \mathrm{kPa}$ is higher than the shear stress value at $0.30 \mathrm{~mm} \mathrm{~min}^{-1}$ and $60 \mathrm{kPa}$. An increase in the displacement values with the increase in the applied normal load (60-180 kPa) was observed. The cause of higher shear stress at $0.74 \mathrm{~mm} \mathrm{~min}^{-1}$ is that the values of the angle of internal friction obtained at $0.74 \mathrm{~mm} \mathrm{~min}^{-1}$ were higher than at $0.30 \mathrm{~mm} \mathrm{~min}^{-1}$. This can also be seen from Eq. (1). The same results for the direct shear test have been reported by Mofiz et al. (2004), Ramirez et al. (2004), and Nakao and Fityus (2008).

At the end of PCA, factor coefficients of identifying qualities were evaluated and the attributes scoring a coefficient value higher than 0.7 in the first three PCA were determined. The results of the PCA are presented in Table 3. The first three principal components (PCs) accounted for $97.401 \%$ of the total variability among the 36 shear speeds for all the traits investigated. The first principal component (PC1), which is the most important component, explained $55.82 \%$ of the total variability and was related to SS3 -6 , SS9, SS11, SS12, SS14 - 15, SS17, SS20 - 22, SS24 - 25, SS28 - 30, SS32 and SS35 - 36. These traits have a great influence on the mechanical properties and silo wall pressures. The second principal component (PC2) had $24.76 \%$ of the total variation in different shear speeds. SS13, SS26 - 27,
SS31 and SS33 contributed positively to PC2. In contrast, SS1, SS10, SS16 contributed negatively to PC2. The third principal component (PC3) exhibited $16.81 \%$ of all shear speeds and was associated with SS2, SS7, SS18, and SS34.

The plot of the angles of internal friction on the first three PCs obtained from analysis of 36 shear speed traits are presented in Fig. 4. The scatter diagram of the angles of internal friction showed that there was a high level of diversity and the angles of internal friction had significant differences in the important shear speeds.

The angle of internal friction grouping of thirty six shear speeds using the clustering algorithm is shown in Fig. 5. The shear speeds were divided into different clusters by their distribution on the dendogram. In the research, seven clusters occurred in the result of the CA, in terms of shear speed traits. Group 1 consisted of five shear speeds. There was a total of seven shear speeds in the biggest Group 2. Groups 3 and 6 had four shear speeds. Groups 4 and 5 contained six shear speeds. However, there were only three shear speeds in Group 7.

Poisson ratio of dry bean ranged from 0.345 to 0.431 (Fig. 6). The relationship between Poisson ratios with the angles of internal friction depending on different shear speed is inversely proportional as shown in Fig. 6. The differences between Poisson's ratios at different shear speeds were statistically significant at $\mathrm{p}<0.01$. Poisson ratio is 
T a b l e 3. Principal component analysis (for the first three PCs) of angles of internal friction studied for shear speeds

\begin{tabular}{|c|c|c|c|}
\hline $\begin{array}{l}\text { Principal component } \\
\text { analysis }\end{array}$ & PC 1 & PC 2 & PC 3 \\
\hline Eigen values & 20.096 & 8.916 & 6.052 \\
\hline Proportion of variation (\%) & 55.823 & 24.767 & 16.811 \\
\hline Cumulative variation (\%) & 55.823 & 80.590 & 97.401 \\
\hline Trait & \multicolumn{3}{|c|}{ Eigen vectors } \\
\hline SS1 & -0.101 & -0.720 & 0.218 \\
\hline SS2 & -0.373 & -0.185 & 0.876 \\
\hline SS3 & 0.835 & 0.002 & -0.550 \\
\hline SS4 & 0.937 & 0.245 & 0.247 \\
\hline SS5 & 0.951 & 0.297 & -0.090 \\
\hline SS6 & 0.764 & 0.427 & -0.484 \\
\hline SS7 & -0.557 & 0.404 & 0.725 \\
\hline SS8 & 0.530 & 0.606 & -0.593 \\
\hline SS9 & 0.994 & -0.065 & 0.085 \\
\hline SS10 & 0.646 & -0.746 & 0.159 \\
\hline SS11 & -0.965 & -0.107 & -0.238 \\
\hline $\mathrm{SS} 12$ & 0.819 & -0.565 & -0.096 \\
\hline $\mathrm{SS} 13$ & -0.399 & 0.910 & 0.110 \\
\hline SS14 & 0.891 & 0.265 & 0.177 \\
\hline SS15 & 0.985 & 0.129 & -0.112 \\
\hline SS16 & 0.362 & -0.845 & 0.393 \\
\hline SS17 & -0.805 & 0.061 & 0.532 \\
\hline SS18 & 0.596 & -0.127 & 0.792 \\
\hline SS19 & -0.556 & 0.638 & 0.512 \\
\hline SS20 & 0.772 & 0.524 & -0.358 \\
\hline SS21 & -0.973 & -0.175 & -0.150 \\
\hline $\mathrm{SS} 22$ & 0.968 & 0.151 & 0.202 \\
\hline SS23 & -0.651 & 0.663 & 0.370 \\
\hline SS24 & 0.886 & 0.404 & 0.188 \\
\hline SS25 & 0.776 & -0.630 & 0.037 \\
\hline SS26 & 0.567 & 0.815 & -0.008 \\
\hline SS27 & -0.561 & 0.785 & 0.255 \\
\hline SS28 & -0.780 & -0.526 & 0.294 \\
\hline SS29 & 0.948 & 0.292 & 0.116 \\
\hline SS30 & 0.839 & -0.039 & 0.538 \\
\hline SS31 & -0.637 & 0.755 & -0.065 \\
\hline $\mathrm{SS} 32$ & 0.821 & 0.261 & 0.481 \\
\hline
\end{tabular}

T a b l e 3. Continuation

\begin{tabular}{cccc}
\hline $\begin{array}{c}\text { Principal component } \\
\text { analysis }\end{array}$ & PC 1 & PC 2 & PC 3 \\
Trait & & Eigen vectors \\
\hline SS33 & -0.452 & 0.880 & 0.146 \\
SS34 & 0.296 & -0.081 & 0.913 \\
SS35 & 0.873 & 0.366 & 0.251 \\
SS36 & 0.804 & 0.187 & 0.548 \\
\hline
\end{tabular}

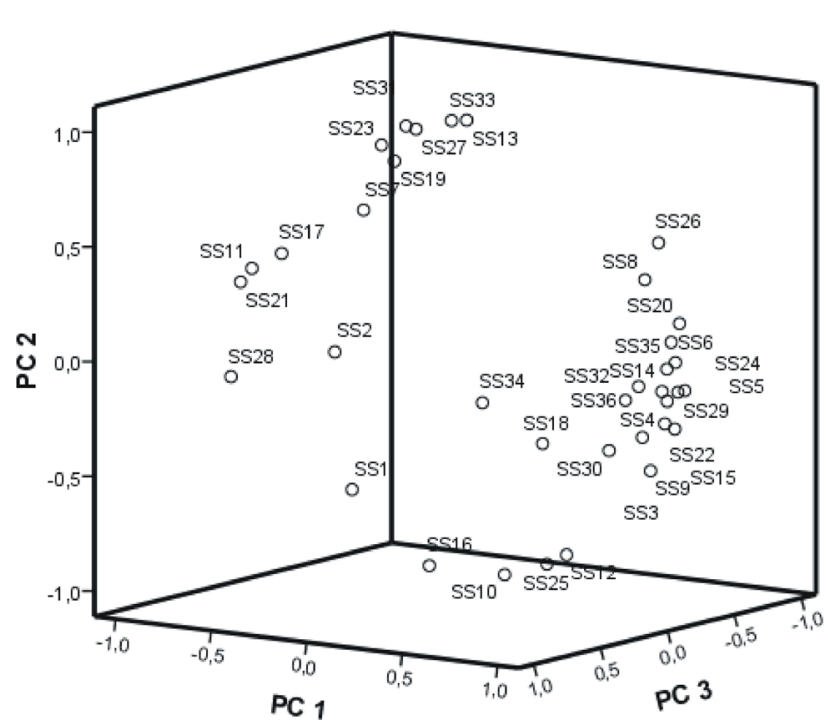

Fig. 4. Scatter diagram based on the first three principal components (PC) axes at thirty six shear speeds.

necessary in design with finite element analysis of wall pressures in storage structures. Poisson ratio was used to determine the minimum slope of flow at the self emptying bin in a silo hopper and the stress distribution in the silo wall at ANSYS finite element software. Molenda et al. (2001) also reported the same results for soybean meal and corn meal. Moya et al. (2006) reported both decreased and increased Poisson ratios at different shear speeds $(0.19$ and $1.02 \mathrm{~mm}$ $\mathrm{min}^{-1}$ ) of various agricultural products (amelia chickpea, flaxseed, lentil, rice, rye, horzal wheat).

The observed values in the lateral pressure ratios according to the different angles of internal friction are shown in Fig. 7. Lateral pressure ratios determined according to thirty six different shear speeds and different methods changed as non-linear with the increase in the shear speed. At the present time, to calculate pressures acting on silo walls, the equation proposed by Eurocode 1 is generally used. Here, a comparison is made between the other methods and Eurocode 1 . The pressure ratio values calculated according 


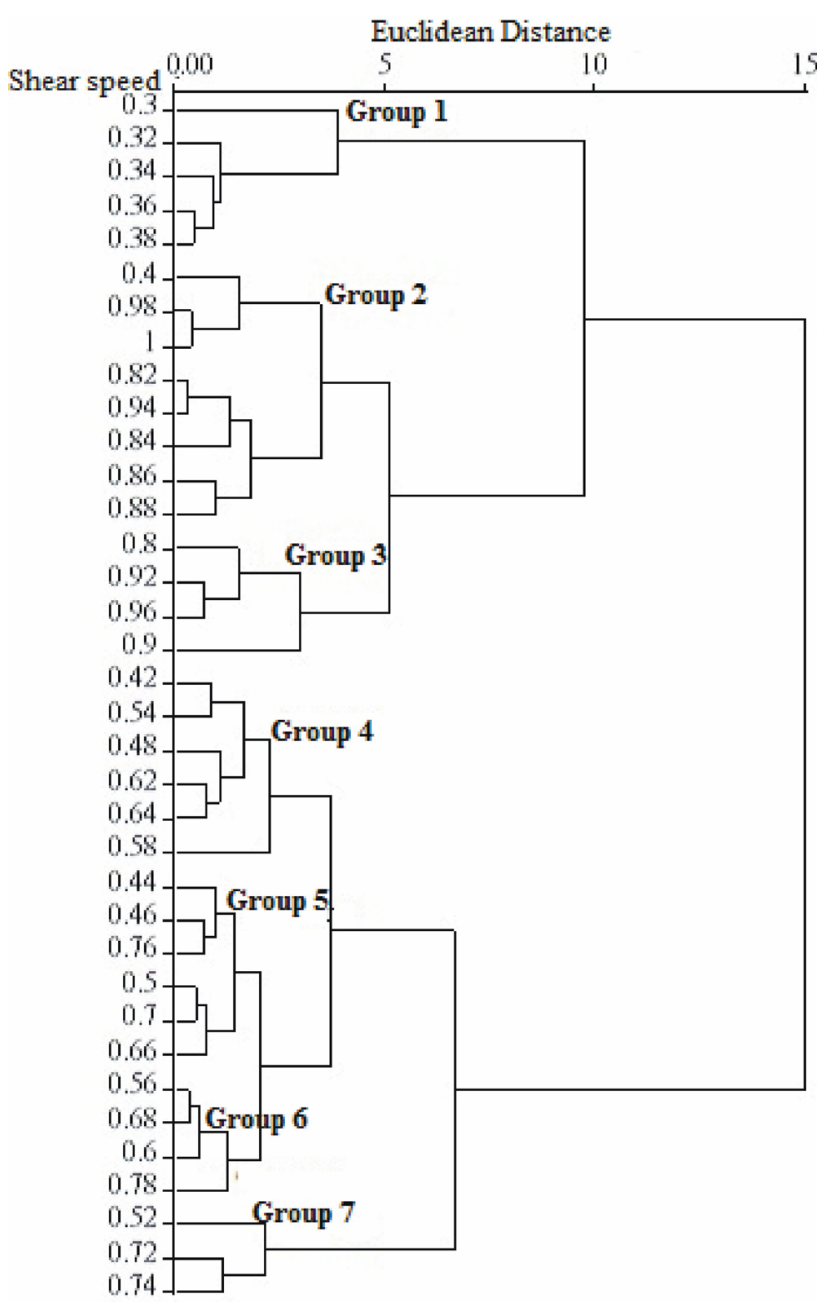

Fig. 5. Dendrogram of the angles of internal friction obtained from cluster analysis based on shear speed traits.

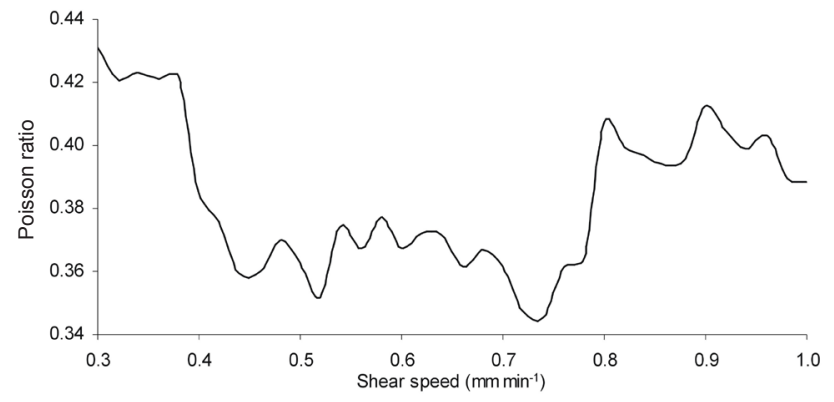

Fig. 6. Poisson ratios concerning different shear speeds.

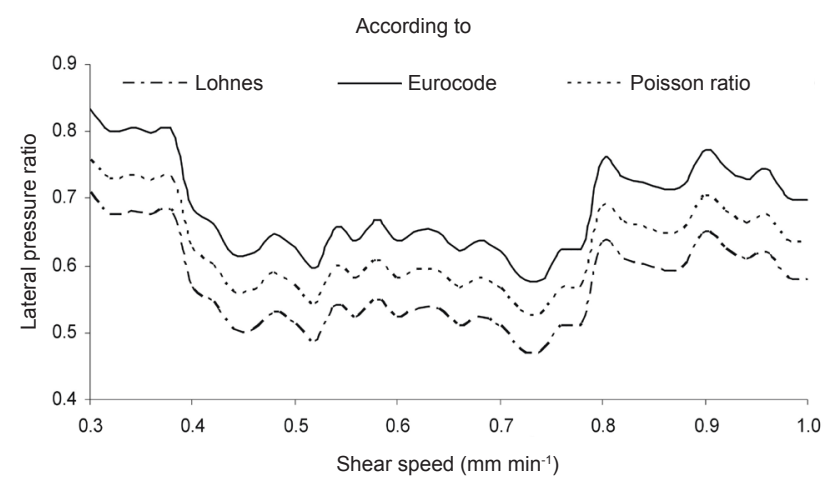

Fig. 7. Lateral pressure ratios according to the different methods.

to Eurocode had higher values than those obtained with the other methods (Fig. 7). The highest value for lateral pressure ratio was determined according to Eurocode 1 (0.757) and the lowest value was determined according to Jaky (1948) (0.470). The differences related to each method were statistically significant $(\mathrm{p}<0.05)$. Similar results have been reported by Molenda et al. (2001) for wheat, and Horabik and Rusinek (2002) for some cereal grains. Lateral pressure ratio is necessary to calculate pressures acting on the walls (standards such as Eurocode1, 2006; DIN1055-6, 1987; AS3774, 1996) in silos.

The filling pressure distributions were calculated for dry bean using the angle of internal friction and lateral pressure ratio at different shear speeds (Fig. 8). The theoretical pressure distributions for the cylindrical silo are also presented in Eurocode 1 (2006). The distribution of vertical pressures along the wall of the silo was significantly influenced by the angle of internal friction and lateral pressure ratio (Fig. 8). The lowest filling pressures were determined in mechanical properties caused by the shear speeds from 0.30 to $0.38 \mathrm{~mm} \mathrm{~min}^{-1}$. This difference leads to the proportional change between the mechanical properties. While the highest value $(16.88 \mathrm{kPa})$ for the vertical pressures was recorded at $0.74 \mathrm{~mm} \mathrm{~min}^{-1}$ shear speed, the lowest value $(5.74 \mathrm{kPa})$ for the horizontal pressures was recorded at $0.36 \mathrm{~mm} \mathrm{~min}^{-1}$ shear speed. Figure 8 shows considerable spread or variation in pressures, especially in the lower portions of the silo. The pressure changes with height in silo walls due to pressures of bulk material have been reported by different researchers. Many researchers have also found a significant influence of grain pressures on the values of the angle of internal friction (Mahapatra and Lan, 2007; Tomas, 2014). 



Fig. 8. Silo vertical pressures occurring at different heights. 


\section{CONCLUSIONS}

1. The influence of shear speed on the mechanical properties can be determined using the direct shear test.

2. The test results showed that the important effect of shear speeds on the shear stress change. The angles of internal friction with the increases in the shear speeds show both increases and decreases.

3. The values of Poisson ratio were dependent on the angle of internal friction. The values of Poisson ratio were significantly different for the different angle of internal friction.

4. The lateral pressure ratio of dry bean decreased and increased depending on increases in the angle of internal friction. The effect of shear speed on these changes is extremely important. The lateral pressure ratio for dry bean was greatest on Eurocode 1, followed according to Poisson ratio and Jaky.

5. The wall pressures decreased and increased during the filling conditions with change in the angle of internal friction. In addition, there was a huge variability in the angle of internal friction among the different shear speeds.

6 . The results obtained suggest that the design of silo structures and postharvest processing equipment may not neglect the features of real pressure distribution developed by the stored material. Therefore, an analysis using finite element programs (ANSYS, FELASH and ABAQUS etc.) in silos and storage structures should be made.

7. This study is the first one to determine angles of internal friction variability at different shear speeds using multivariate statistical analyses. In conclusion, these findings are important for the mechanical and physical properties of different shear speed studies for all agricultural materials undertaken in the future.

\section{REFERENCES}

AOAC, 1984. Official method of analysis 14th Ed., Association of Official Analytical Chemists. Washington, DC, USA.

ASTM, 2000a. D3080-90: Standard test method for direct shear test of soils under consolidated drained conditions. In: Annual Book of ASTM Standards. West Conshohocken, PA: American Society for Testing and Materials.

ASTM, 2000b. D6128-97: Standard test method for shear testing of bulk solids using the Jenike shear cell. In: Annual Book of ASTM Standards. West Conshohocken, PA: American Society for Testing and Materials.

AS3774, 1996. Loads on bulk solids containers. Standards Australia, Sydney, Australia.

DIN1055-6, 1987. Design loads for buildings: loads in silo bins, Deutsches Institut fur Normung, Berlin, Germany.

Eurocode 1, 2006. EN 1991-4, Eurocode 1: Basis of Design and Actions on Structures, Part 4 - Silos and Tanks. European Committee for Standardisation, Brussels.

Eurocode 3, 2004. Design of Steel Structures (EN 1993-1-3), Part 1-3: General Rules-Supplementary Rules for Cold Formed Thin Gauge Members and Sheeting. European Committee for Standardisation, Brussels, Belgium.
FAOSTAT, 2012. World crop production statistics. Food and Agricultural Organization of United Nations Statistical Database Online Services.

Ganesan V., Rosentrater K.A., and Muthukumarappan K., 2005. Flowability and handling characteristics of bulk solids and powders - A review. ASAE Annual Int. Meeting, ASAE Tampa Convention Center, July 17-20, Tampa, Florida.

Härtl J. and Ooi J.Y., 2008. Experiments and simulations of direct shear tests: porosity, contact friction and bulk friction. Granular Matter, 10, 263-271.

Horabik J. and Rusinek R., 2002. Pressure ratio of cereal grains determined in uniaxial compression test. Int. Agrophysics, $16,23-28$.

Jaky J., 1948. Pressures in silos. Proc. 2nd Int. Conf. Soil Mechanics and Foundation Engineering, 1, 103-107.

Lohnes R.A., 1993. Lateral stress ratios for particulate materials. Powder Handling and Processing, 5, 331-335.

Mahapatra A.K. and Lan Y., 2007. Postharvest handling of grains and pulses. In: Handbook of Food Preservation (Ed. M.S. Rahman). CRC Press, New York, USA.

Mofiz S.A., Rhaman M.M., and Alim M.A., 2004. Stress-strain behaviour and model prediction of reinforced residual soil. 15th Southeast Asian Geotechnical Soc. Conf., November 22-26, Bagkok, Thailand.

Molenda M., Montross M.D., Horabik J., and Ross I.J., 2001. Mechanical properties of granular feed ingredients. ASAE Annual Int. Meeting, Sacramento Convention Center, July 30 - August 1, Sacramento, CA, USA.

Moya M., Ayuga F., Guaita M., and Aguado P., 2002a. Mechanical properties of granular agricultural materials considered in silos design. 15th ASCE Eng. Mechanics Conf., Columbia University, June 2-5, New York, USA.

Moya M., Ayuga F., Guaita M., and Aguado P., 2002b. Mechanical properties of granular agricultural materials. Trans. ASAE, 45, 1569-1577.

Moya M., Guaita M., Aguado P., and Ayuga F., 2006. Mechanical properties of granular agricultural materials. Part 2. Trans. ASAE, 49, 479-489.

Nakao T. and Fityus S., 2008. Direct shear testing of a marginal material using a large shear box. Geotechnical Testing J., 31, 393-403.

Qu Q., Negi S.C., and Jofriet J.C., 2001. Storage of cohesive material in silos. Part 2: Parametric study. Powder Handling Proc., 13, 27-30.

Ramirez A., Moya M., and Ayuga F., 2004. Determination of mechanical properties of agricultural powder materials and sugar to be used in silos design. ASAE/CSAE Annual Int. Meeting, Fairmont Chateau Laurier, The Westin, Government Centre Ottawa, August 1-4, Ontario, Canada.

Tomas J., 2014. Silo and bunker pressure calculations. Faculty of Process and Systems Engineering, Mechanical Process Engineering, Magdeburg, Germany.

USDA, 2012. Dry Beans. United Stated Department of Agriculture, Economic Research Service, Washington, DC, USA.

Zou Y. and Brusewitz G.H., 2001. Angle of internal friction and cohesion of consolidated ground marigold petals. Trans. ASAE, 44, 1255-1259. 